\section{Prevalence of Oral}

Mucosal Lesions and Oral

Health-Related Quality

of Life among

Adolescents in a Rural

Nigerian Population

*Adeola J. AKANDE, **Omolara G. UTI, **Oyinkan O. SOFOLA.

* Department of Preventive Dentistry, Lagos University Teaching Hospital, Lagos State, Nigeria.

** Department of Preventive Dentistry, Faculty of Dental Sciences, College of Medicine, University of Lagos/Lagos University Teaching Hospital, Lagos State, Nigeria.

\author{
Correspondence \\ Adeola J. Akande, \\ Department of Preventive Dentistry, Lagos University \\ Teaching Hospital, Idi-Araba, Mushin Local \\ Government, Lagos State, Nigeria \\ Email:aaredrakande@gmail.com
}

\section{ABSTRACT}

Background: Oral mucosal lesions affect people of all age groups, and vary in presentation; from asymptomatic to severely debilitating. Studies reporting the prevalence and effects of these lesions in adolescents are generally few compared to those describing the demography of dental caries and other oral diseases.

Objective: To determine the prevalence of oral mucosal lesions, factors that contribute to the prevalence, and the association with the oral-health related quality of life (OHRQoL) of adolescents in the population.

Methods: A cross-sectional survey was done on 240 secondary school students aged 10-19 from three secondary schools selected using multi-stage cluster random sampling. A pre-designed questionnaire was used to collect demographic information, presence of systemic illness, and oral habits. Oral-health related quality of life was assessed using the oral-health impact profile (OHIP-14), and intraoral examination was performed within the school premises by a single trained investigator.

Results: A total of 33 participants (13.7\%) had oral mucosal lesions. Overall, commissural lip pits (5.0\%) were the most prevalent, while geographic tongue and irritation fibroma ( $0.4 \%$ each) were the least prevalent lesions. The mean OHIP14 score of the participants in this study was $7.17 \pm 8.64$. Participants with systemic diseases and cheek biting habits had statistically significant worse scores than those without either.

Conclusion: The most prevalent oral mucosal lesions in the adolescent age group are those of developmental origin. Quality of life was negatively impacted by the presence of systemic diseases as well as cheek biting habit.

Keywords: Oral mucosa, Oral health, Quality of life.

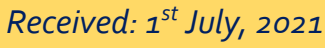 \\ Revision: $11^{\text {th }}$ Sept, 2021 \\ Accepted: $12^{\text {th }}$ Sept, 2021
}

Adeola J. Akande

https://orcid.org/ 0000-0002-5093-9396

Omolara G. Uti

https://orcid.org/ 0000-0003-3023-5006

Oyinkan O. Sofola

https://orcid.org/0000-0003-3023-5006

Citation: Akande AJ, Uti OG, Sofola OO. Prevalence of Oral Mucosal Lesions and Oral Health Related Quality of Life among Adolescents in a Rural Nigerian Population. Nig J Dent Res 2022; 7(1): 10-19 


\section{INTRODUCTION}

Oral health is important to the quality of life of all individuals, and the oral mucosa among other functions, serves as a protective barrier against trauma, pathogens, and carcinogenic agents. ${ }^{1}$ It is also a mirror reflecting the general state of health as it is well established that several systemic conditions manifest orally and the oral mucosa may be the first pointer to an underlying systemic pathology.

Researchers have defined an oral mucosal lesion $(\mathrm{OML})$ as any abnormal alteration in colour, surface aspect, swelling or loss of integrity of the oral mucosa surface; and prevalence ranging from $4.9 \%-64.7 \%$ has been reported worldwide. ${ }^{2}$ These lesions may be of a benign nature, discovered during routine dental checkup or oral examination for other lesions which interfere with daily social activities in affected patients through impact on mastication, swallowing, speech, and aesthetics.

They affect all age groups to varying degrees and sociodemographic factors are well known to contribute to the prevalence of diseases. For example, children are more likely to have traumatic and infectious lesions while adults frequently have denture and tobacco-related lesions, such as stomatitis, hyperplasia and leukoplakia. ${ }^{3,4}$ It has also been observed that certain pathologies have a predilection for the younger age group such as Langerhans cell histiocytosis and some types of Lymphoma, Leukemia, and Hemangioma which may differ considerably in their histopathology, clinical behavior, and management. ${ }^{5}$

There have been recent changes in the trend of tobacco use by adolescents and young adults, with an increased use reported in many jurisdictions. This has resulted in a higher diagnosis of oral potentially malignant lesions in this age group that was traditionally at very low risk. ${ }^{6}$

Epidemiologic studies of OMLs are not as frequent as studies involving dental caries or Periodontitis, ${ }^{3}$ and there are relatively few reports in the literature regarding oral mucosal conditions in children; with Caries and cancer therapy-related mucosal disorders being the most commonly discussed. ${ }^{4}$ This is even more so in the African space where literature searches on oral mucosal lesions often return results for specific lesions like oral ulcerations et cetera.

Lately, there has been a transition from the traditional clinical treatment outcome criteria which focus on diseases only (such as caries, periodontitis, gingivitis et cetera.) to a more patient-centered oral health delivery systems that focus on a person's social, emotional and physical experience. In other words, it should address patients' health complaints and take into consideration the impact of the patients' illness on their quality of life. ${ }^{7}$ This has led to the growth of the concept of Oral-Health Related Quality Of Life (OHRQOL) to serve as adjuncts for measuring outcomes associated with diseases/conditions.

Sawyer, Taiwo, and Mosadomi ${ }^{8}$ authored one of the few broad population-based epidemiological studies of OMLs available in Nigeria in 1984. There is a need to revisit the study of OMLs to probe for contributors to the presence of these lesions as well as to describe their effects on the oral-health related quality of life of the adolescent population.

\section{METHODOLOGY \\ STUDY DESIGN AND LOCATION}

This is a descriptive cross-sectional study carried out in Ifo, a Local Government Area in Ogun State, about $51 \mathrm{~km}$ from Abeokuta, the capital of Ogun State in South West Nigeria. It is a rapidly developing area which is $46 \mathrm{~km}$ from Ikeja, the capital city of cosmopolitan Lagos. Participants were randomly selected from the secondary school students in the area.

\section{STUDY SUBJECTS AND SELECTION}

Six schools across the local government were selected by multi-stage cluster random sampling out of which three (two private and one public) schools agreed to participate. Each school was further divided into classes and random sampling was used to select participating classes and students to make up the total sample size. Those included in this study were permanent residents of Ifo Local Government area. Parental consent was obtained and those students with physical/mental disability were excluded.

\section{DATA COLLECTION}

Ethical approval was sought and obtained from the Lagos University Teaching Hospital (LUTH) Health Research Ethics Committee before commencement of data collection. Informed written consent of parents/guardians as well as assent of willing participants was also gotten 
A structured, self-administered questionnaire was used to collect personal data, social habits, as well as presence of any systemic illness or chronic diseases. The Oral-Health Related Quality of Life was assessed using the shortened version of the Oral Health Impact Profile (OHIP-14) ${ }^{9}$ self-filled questionnaire that focuses on seven dimensions of impact of oral lesions on the following aspect of human life: functional limitation, pain, psychological discomfort, physical disability, psychological disability, social disability and social handicap. Participants were required to respond according to frequency of impact on a 5-point Likert scale coded; never (score o), rarely (score 1), occasionally (score2), often (score 3) and always (score 4) using a twelve-month recall period. The maximum obtainable score using the OHIP-14 is 56.

An intraoral exam was performed in a well-lit space in each school environment. Materials used for the examination include: disposable examination gloves, tongue depressor, and mouth mirror. The Color Atlas Of Clinical Oral Pathology (2nd edition) ${ }^{10}$ was used as a reference for the diagnosis of oral mucosa conditions. Chronic inflammatory diseases of periodontal origin were excluded, and oral lesions with recurrent nature were only recorded if observed at the time of examination.

\section{DATA ANALYSIS}

Data was analyzed using the Statistical Package for Social Sciences software, (SPSS) version 23, Chicago III, SPSS Inc. Descriptive statistics was used to describe the mean age and standard deviation of the students' age as well as the population mean OHIP14 score and the scores of the different subgroups for example: those with systemic diseases, cheek biting et cetera.

Chi-square test was used to assess the relationship between OMLs and gender, cheek biting habit and other variables. The independent t-test was used to test the relationship between mean OHIP-14 scores and the different variables. Confidence interval was set at $95 \%$ for all the analysis and statistical significance was inferred at $p<0.05$.

\section{RESULTS}

A total of 240 copies of questionnaire with complete information and signed parental consent forms were selected for analysis out of the 264 copies of questionnaire distributed - a response rate of $91 \%$. The analyzed data comprises of $113(47.1 \%)$ males and $127(52.9 \%)$ females with a mean age of $13.98 \pm 2.04$ years. Chronic diseases or systemic illness was present in $16.7 \%(n=28)$ of the participants. The cheek biting habit was $14.2 \% \quad(n=34)$ while only $1(0.4 \%)$ participant reported the use of tobacco in the form of cigarette. See table 1.o.

Oral mucosal lesions (OMLs) were seen in 33 students; a prevalence of $13.7 \%$. Nineteen (57.6\%) of the lesions were developmental, twelve (36.4\%) ulcerative, one $(3 \%)$ exophytic, and one (3\%) was an inflammatory lesion. Overall, Commissural lip pits $(n=12 ; 5.0 \%)$ was the most prevalent, followed by traumatic ulcer $(n=8 ; 3.3 \%)$, ankyloglossia $(n=7 ;$ $2.9 \%)$, recurrent aphthous stomatitis $(n=4 ; 1.7 \%)$, geographic tongue and Fibroma of the tongue $(n=1 ;$ $0.4 \%$ each) respectively. In addition, 97 of the students had pigmented and white mucosal variants, namely; generalized physiologic pigmentation $(n=65 ; 27.1 \%)$, and Linea Alba $(n=32 ; 13.3 \%)$. See table 2.0.

The OMLs involved 6 different mucosal sites, namely: floor of the mouth $(n=1 ; 3 \%)$, soft palate $(n=1 ; 3 \%)$, buccal mucosa $(n=5 ; 15.15 \%)$, labial mucosa $(n=5 ; 15.15 \%)$, tongue $(n=9 ; 27.3 \%)$, labial commissure $(n=12 ; 36.4 \%)$.

The mean OHIP-14 score of the students in this study was $7.17 \pm 8.64$. The physical pain subscale recorded the highest impact with 50.8\%, followed by psychological discomfort (32\%), physical disability (28.6\%), psychological disability (24\%), functional limitation (23.4\%), social disability (13.9\%), and social handicap (10\%). See table 3.0.

The mean OHIP-14 score of patients with oral mucosal lesions was $7.54 \pm 8.63$, while participants without lesions had a mean score of $6.84 \pm 8.68$. There was a statistically significant relationship between OHROOL and presence of systemic conditions ( $p=$ o.03). See table 4.0. 
Oral mucosal lesions and OHRQoL in Nigerian adolescents

Table 1: Socio-demographic distribution of Oral mucosal lesions

Sociodemographic characteristics of subjects. $\mathrm{N}=240$

\begin{tabular}{lllll}
\hline Variables & $\begin{array}{l}\text { OMLs present } \\
\text { (\% of population) }\end{array}$ & $\begin{array}{l}\text { OMLs absent } \\
\text { (\% of population) }\end{array}$ & $\begin{array}{l}\text { Total no (\% of study } \\
\text { population) }\end{array}$ & P-value \\
\hline Gender & & & & \\
Male & $12(5)$ & $101(42.1)$ & $113(47.1)$ & 0.18 \\
Female & $21(8.7)$ & $106(44.2)$ & $127(52.9)$ & \\
Age group & $19(7.9)$ & $111(46.3)$ & $130(54.2)$ & \\
$10-14$ & $12(5)$ & $93(38.8)$ & $105(43.8)$ & 0.53 \\
$15-17$ & $02(0.8)$ & $3(1.2)$ & $05(2.0)$ & \\
$18-19$ & & & & \\
Systemic disease(s) & $06(2.5)$ & $22(9.2)$ & $28(11.7)$ & 0.21 \\
Present & $27(11.2)$ & $185(77.1)$ & $212(88.3)$ & \\
Absent & & & & \\
Cheek biting habit & $04(1.7)$ & $30(12.5)$ & $34(14.2)$ & 0.72 \\
Present & $29(12.1)$ & $177(73.7)$ & $206(85.8)$ & 0.69 \\
Absent & & & & \\
Tobacco use & 0 & $01(0.4)$ & $01(0.4)$ & $239(99.6)$ \\
Present & $33(13.7)$ & $206(85.8)$ & \\
Absent & & & \\
\hline
\end{tabular}

Table 2: Oral mucosal lesions prevalence with sex and age distribution.

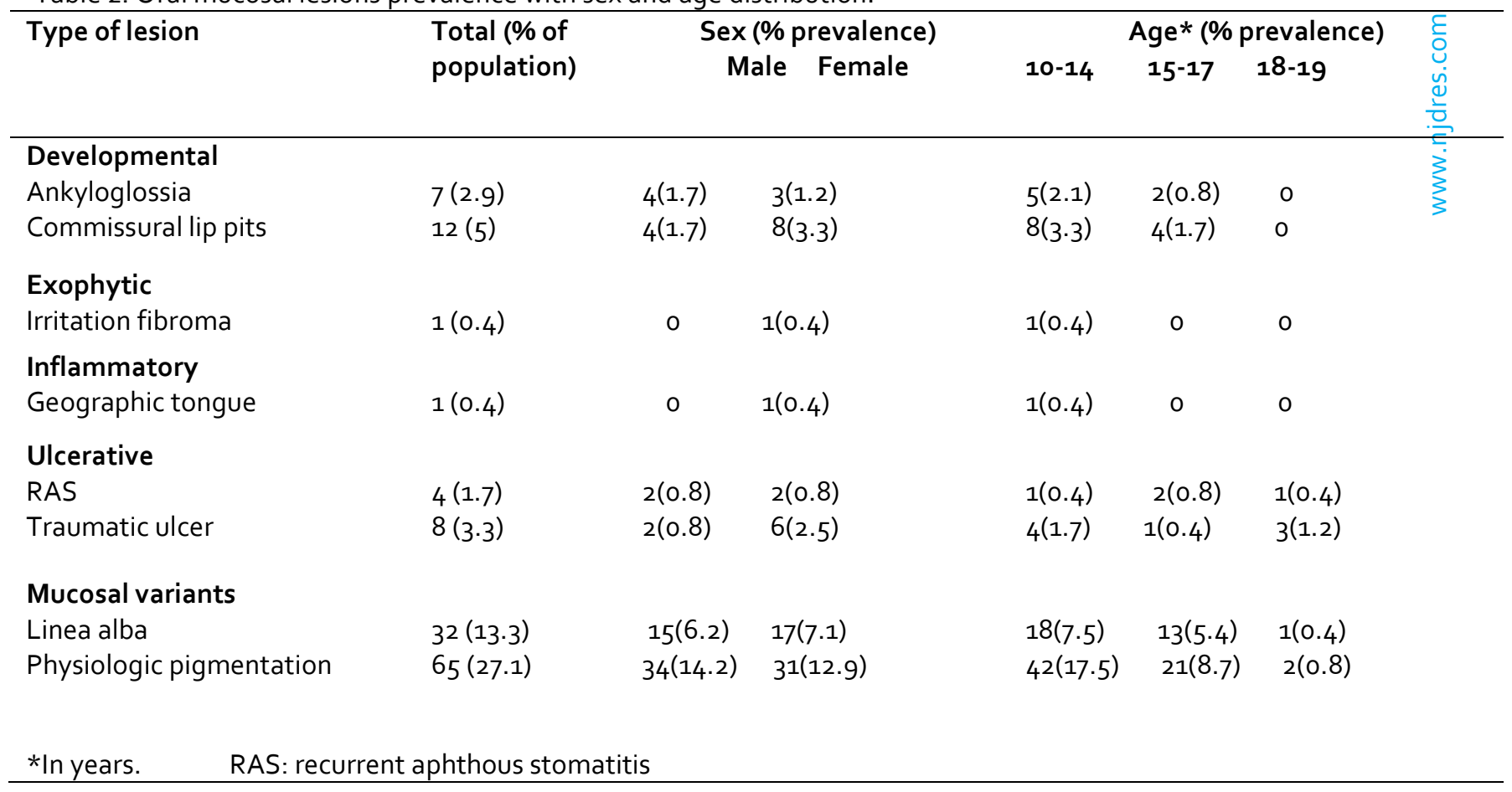


Table 3: Reported impacts on the activities measured by the OHIP-14

\section{OHIP}

Subscale
Question/Daily Activities

ORAL-HEALTH

No Impact

\section{$\mathrm{n}(\%)$}

1

Functional

limitation

2 Physical pain

$3 \quad$ Psychological discomfort

$4 \quad$ Physical disability

$5 \quad$ Psychological disability

6 Social disability

7 Social handicap
I. Had trouble pronouncing any words

ii. Felt that sense of taste has worsened

lii. Had painful aching

Iv. Found it uncomfortable to eat any foods

$\checkmark$. Been self-conscious

Vi. Felt tense

Vii. Diet been unsatisfactory

Viii. Had to interrupt meals

Ix. Found it difficult to relax

$X$. Been a bit embarrassed

$X i$. Had been a bit irritable with other people

Xii. Had difficulty doing usual jobs

Xiii. Felt that life in general was less satisfying

Xiv. Been totally unable to function
Impact
Im)

208(86.6)

216(90)

$172(71.7)$

186(77.5)

198(82.6)

205(85.4)

213(88.8)

198(82.6)

$211(88)$

211(88)

224(93.3)

223(92.8)

228(95)

228(95)
32(13.4) Sum $=$

$24(10) \quad 23.4 \%$

68(28.3) Sum =

$54(22.5) \quad 50.8 \%$

42(17.4) Sum =

35(14.6) $32 \%$

27(11.2) Sum =

42(17.4) $28.6 \%$

29(12) Sum =

29(12) $\quad 24 \%$

16(6.7) Sum =

$13.9 \%$

$17(7.2)$

12(5) Sum =

$10 \%$

12(5)

Table 4: Association between variables and mean OHIP-14 scores

\begin{tabular}{|c|c|c|c|c|c|c|}
\hline VARIABLE & & $\mathrm{N}(\%)$ & $\begin{array}{l}\text { Mean } \\
\text { score }\end{array}$ & $\begin{array}{l}\text { Standard } \\
\text { deviation }\end{array}$ & T-test & $P$ value \\
\hline \multirow[t]{2}{*}{ Gender } & Male & $113(47.1 \%)$ & 7.27 & 9.55 & 0.393 & 0.695 \\
\hline & Female & $127(52.9 \%)$ & 6.83 & 7.74 & & \\
\hline \multirow[t]{2}{*}{ Systemic condition(s) } & Absent & $212(88.3 \%)$ & 6.60 & 8.48 & -2.129 & $0.034^{* *}$ \\
\hline & Present & $28(16.7 \%)$ & 10.20 & 9.15 & & \\
\hline \multirow[t]{2}{*}{ Oral mucosa lesions } & Absent & $207(86.6 \%)$ & 6.81 & 8.64 & & 0.320 \\
\hline & Present & $33(13.7 \%)$ & 8.42 & 8.52 & 0.997 & \\
\hline \multirow[t]{2}{*}{ Mucosal variants } & Absent & $143(59.6 \%)$ & 6.91 & 8.55 & 0.298 & 0.766 \\
\hline & Present & $97(40.4 \%)$ & 7.26 & 8.80 & & \\
\hline \multirow[t]{2}{*}{ Cheek biting habit } & Absent & $206(85.8 \%)$ & 6.08 & 7.53 & $4 \cdot 301$ & $0.000^{* *}$ \\
\hline & Present & $34(14.2 \%)$ & 12.63 & 12.05 & & \\
\hline$* * \mathrm{P}<0.05$ & & & & & & \\
\hline
\end{tabular}

\section{DISCUSSION}

Oral mucosal lesions (OMLs) are known to have varying prevalence in different parts of the world. The prevalence of $13.7 \%$ recorded in this study is slightly lower than the $16.6 \%$ reported by Chauhan et $\mathrm{al}^{11}$ in a similar population-based study in India. However, this prevalence is much lower than in other studies conducted in Europe $\mathrm{e}^{12,13}$ and Asia ${ }^{1,14,15}$ where values ranging from $24.2 \%-58.1 \%$ were reported. A possible explanation for these prevalence variations is the characteristics of the study populations especially the difference in age bracket. While Chauhan et $\mathrm{al}^{11}$ and Sandeepa et al ${ }^{15}$ studied a narrow age bracket (12-15 years and 16-17 years 
respectively), Amadori et $\mathrm{al}^{12}$ included a broader adolescent age group as done in this study.

Another significant factor is the recording of conditions regarded as normal variants such as Linea alba, Fordyce granules, physiologic pigmentation etc. as mucosal lesions by several authors. These variants were not recorded as OMLs in this study. Instead, those observed in participants were simply recorded as physiologic variants.

Majority of the lesions in this study were in females $(63.6 \%)$, compared to $36.4 \%$ in males, which may be a reflection of the higher female participation in the study, though this was not statistically significant $(p=0.18)$. In India, Sandeepa et $\mathrm{al}^{15}$ reported a similar result. Kamble et $\mathrm{al}^{14}$ however included the adult population in their study and recorded a very high male prevalence of OMLs at $70.8 \%$, with majority of the lesions seen being tobacco-related.

Cheek biting habit is usually not a cause of concern because it is asymptomatic and is less objectionable than non-nutritive sucking habits or nail biting behaviors. ${ }^{16}$ However, young patients with this habit require special attention when undergoing dental treatment requiring anesthesia to avoid biting their soft tissues and causing injuries intra or post operatively. Also, chronic biting may result in lesions of the oral mucosa known as morsicatio mucosae oris which are observed on the buccal mucosa, labial mucosa and lateral tongue. Morsicatio buccarum (cheek biting lesion of the buccal mucosa) was reported in $4.7 \%$ of the adolescent Italian ${ }^{12}$ population but none was found in this study.

It is important to distinguish between cheek biting and Linea alba which has a prevalence of $13.3 \%$ in this study. Linea alba is a benign hardening of the buccal mucosa due to excess keratin deposition (see figure 3.0). It is more frequently seen in adults than in children $^{(17)}$ and generally considered a physiological variation, rather than a pathologic lesion. However, Ali et $\mathrm{al}^{1}$ and Sandeepa et $\mathrm{al}^{15}$ reported it as the most prevalent oral mucosal lesion in their study of Kuwaiti and Indian populations, reporting a prevalence of $12.3 \%$ and $11.1 \%$ respectively.

Possible causes of linea alba include cheek biting, malocclusion, and friction from dentures or orthodontic appliances. It is asymptomatic but may also be mistaken for leukoplakia ${ }^{17}$ - a potentially malignant lesion, thereby causing the patient psychological discomfort. Treatment involves addressing the underlying cause and/or management of habits that exacerbates it.

The tobacco use recorded was in the form of cigarette smoking and the prevalence (0.4\%) was very low, which contrasts Adeyeye $0,{ }^{18}$ who reported a $12.5 \%$ smoking prevalence among secondary school students in metropolitan Lagos, the economic capital of Nigeria. Amadori et al ${ }^{12}$ reported a $15.7 \%$ smoking prevalence in Italian adolescents which was significantly associated with hairy tongue, smoking associated melanosis, and focal hyperkeratosis ( $p<$ $0.05)$. The very low prevalence of tobacco use in this study may account for the absence of potentially malignant lesions and other tobacco related lesions. Commissural lip pits was found in $5.0 \%$ of the study population, making it the most prevalent mucosal lesion (see figure 3.0). They are small mucosal invaginations that occur at the corners of the mouth on the vermillion. It is higher than the $2.9 \%$ previously reported in Nigerian study by Sawyer et $\mathrm{al}^{8}$ and a prevalence of $2.65 \%$ in Indians reported by Tailor and Joshi ${ }^{19}$. However, a much higher prevalence was reported by Schaumann et $\mathrm{al}^{20}$ in a North American black population where it was present in $21.13 \%$ of the population. This suggests a higher prevalence in blacks.

There was a female prevalence twice that of the male, and $91.7 \%$ of the pits were bilateral with $8.3 \%$ being unilateral; occurring on the left side alone. Other than aesthetic defects, commissural lip pits may be misdiagnosed as chronic angular cheilitis ${ }^{(19)}$ and is also associated with other congenital defects such as popliteal pterygium syndrome and preauricular pits. ${ }^{20}$

Oral ulceration is generally defined as damage of both epithelium and lamina propria of the oral mucosa leading to discontinuity of the oral mucosa. ${ }^{21}$ It is regarded as one of the commonest reasons for dental consultations and has been associated with impaired quality of life. This study reported an oral ulcer prevalence of $5.0 \%$ (Recurrent aphthous stomatitis (RAS); $1.7 \%$ and Traumatic ulcers; 3.3\%). Different Nigerian studies ${ }^{21,22}$ have reported oral ulcers prevalence ranging from $1.3 \%$ to $20 \%$ with RAS being the most frequently reported. However, these studies involved a wider age range and recorded more types of ulcerations than the two seen in this study. While the cases of traumatic ulcers seen in this study were tongue and lip injuries from sports 
or accidental trauma from cheek biting, the precise aetiology of the RAS cases could not be ascertained. Ünür et $\mathrm{al}^{13}$ reported a similar oral ulcerations prevalence (traumatic ulcers; 3.13\%, RAS; 2.3\%), while an Italian study ${ }^{12}$ involving both outpatients and inpatients recorded a higher traumatic ulcer prevalence of $3.47 \%$ and an RAS prevalence of $4.4 \%$ with the latter being more frequent in females and strongly associated with coeliac disease and anemia $(p<0.005)$. No gender or systemic disease association was found with RAS in our study.

Ankyloglossia, also known as tongue tie, refers to the presence of a short lingual frenulum, which is a fibromucosal fold that connects the ventral surface of the tongue to mucosa of floor of the mouth. It may cause functional impairments like poor speech articulation or feeding problems, for example the inability to lick ice cream due to restriction in tongue elevation and protrusion. It may be attributed to its X-linked genetic characteristic with or without associated cleft lip, cleft palate or hypodontia and familial cases have been reported. ${ }^{23}$

A prevalence of $2.4 \%$ was recorded which is higher than the reports of Sawyer et $\mathrm{al}^{8}$ who reported a prevalence of $0.2 \%$, but it is lower than the $4.4 \%$ recorded by Sandeepa et al ${ }^{15}$ in a study involving a narrow age group of 16-17 year old students. It was the second joint most common tongue lesion in Kaduna State, Nigeria at $\mathbf{1 2 . 9 \%}$ as reported by Fomete et al. ${ }^{24}$

A higher male prevalence was observed similar to what was recorded in Port-Harcourt, Nigeria by Osuji et $\mathrm{al}^{23}$ where a male to female ratio of 2.2 to 1 was seen. This suggests a higher male prevalence of ankyloglossia in Nigeria. It is mostly asymptomatic in older people and may resolve spontaneously during growth. Some individuals may compensate adequately for their decreased tongue mobility ${ }^{23}$ while other patients have persistent associated problems which only improve with surgical treatment which can be frenulotomy, frenulectomy or frenuloplasty, depending on the degree of tonguetie.

Geographic tongue, also known as erythema migrans, is a condition of uncertain aetiopathogenesis that may also affect other oral mucosal sites including the floor of the mouth, buccal mucosa, and gingiva. It has been associated with stress, hormonal changes, immunologic conditions, fissured tongue, and sometimes a positive family history. A prevalence of $0.4 \%$ was recorded in this study which is almost at par with the $0.3 \%$ previously reported by Sawyer et al. ${ }^{8}$ The prevalence in Turkey ${ }^{13}$ is higher at $1.72 \%$ and a prevalence ranging from $0.2 \%-2.8 \%$ has been recorded in India. $11,14,15$

The geographic tongue seen in this study was multifocal, involving the anterolateral part of the tongue dorsum and extending to the ventral tongue surface (see figure 1), with erythematous areas bounded by a slightly elevated keratotic band. Erythema migrans lesions are often asymptomatic though soreness sometimes occurs, especially with salty or spicy foods. They are associated with spontaneous remission and recurrences, which may make recording an exact prevalence difficult. No treatment is usually required but symptomatic lesions may be treated with topical corticosteroids. ${ }^{24}$ Irritation fibroma was the only exophytic lesion recorded in this study. It is regarded as a reactive hyperplastic mass derived from connective tissue of the submucosa. A prevalence of $1.07 \%$ was previously reported in Nigeria ${ }^{24}$ which is higher than the $0.4 \%$ recorded in the present study. However, our report is almost at par with the $0.55 \%$ and $0.6 \%$ recorded in India ${ }^{(14,15)}$. The lesion in our study presented as a sessile mass of about $1 \mathrm{~cm}$ in diameter on the anterior third of the tongue dorsum. See figure 2.0. It had the same color as surrounding tongue mucosa and was not ulcerated or symptomatic. The patient was counseled on the need for excisional biopsy of the tissue to prevent further trauma and rule out any potentially malignant lesion

The gingiva is the most frequently pigmented and readily seen intra-oral tissue and the attached gingiva shows darker colour shades than the other parts. ${ }^{25}$ However, physiologic pigmentation usually does not present a systemic problem though individuals may be concerned about the aesthetics of a black or dark brown gingiva especially in those with a 'gummy smile' or those requiring dentures. Hence, it may be considered a psychological problem affecting the quality of life and requiring treatment. ${ }^{26}$ It is generally considered as a physiologic variant, and not a lesion. A generalized physiologic pigmentation prevalence of $27.1 \%$ was recorded in this study, a value much higher than $3.8 \%$ and $12.1 \%$ reported in Asia $^{1,11}$ 


\section{Figure 1: Geographic tongue}

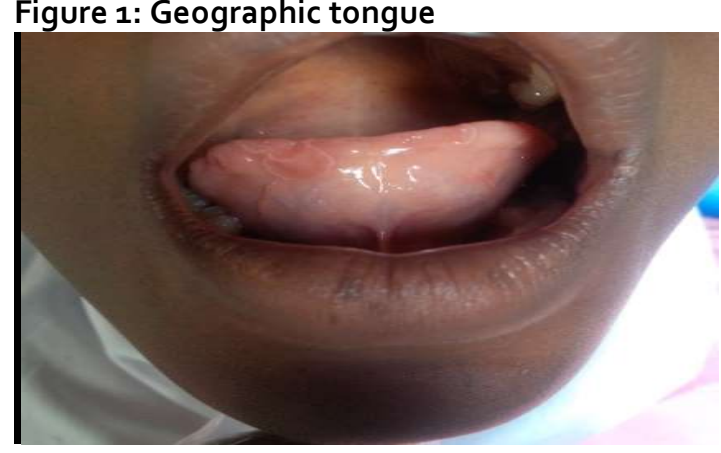

Figure 2: Irritation fibroma

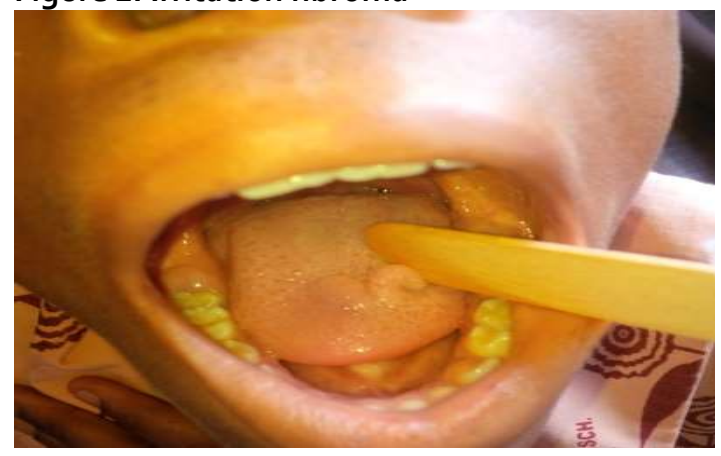

Figure 3: Commissural lip pit and linea alba

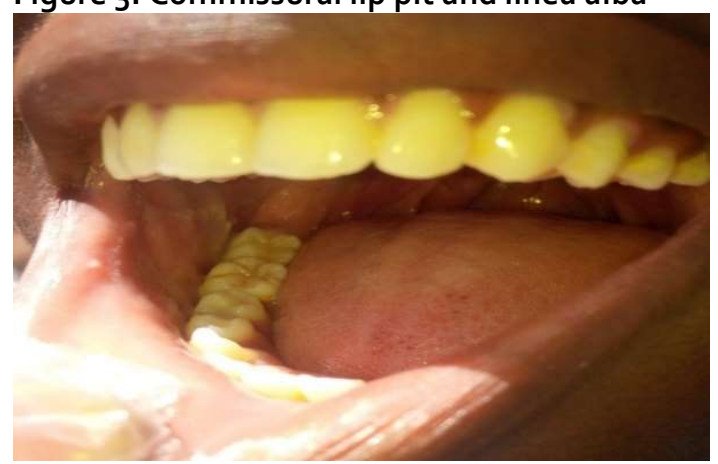

\section{ORAL-HEALTH RELATED QUALITY OF LIFE (OHRQOL)}

The mean OHIP-14 score in this study was $7.17 \pm 8.60$ which is lower than a previous report among Nigerian ${ }^{27}$ undergraduates where the mean score was $10.43 \pm 7.85$. However, both studies suggest a better OHRQoL in the younger population compared to older groups as shown in a Spanish geriatric study ${ }^{28}$ which recorded a mean score of $19.23 \pm 10.58$. Similar to what was reported by Isiekwe et al, ${ }^{27}$ the physical pain subscale recorded the highest impact at
$50.8 \%$, while social handicap recorded the least impact at $10 \%$ (see table 3.0 ). This result suggests that oral mucosal lesions have not socially handicapped the study population.

Our study showed no statistically significant gender association with OHRQoL $(p=0.695)$ which is in agreement with Isiekwe et $\mathrm{al}^{27}$ and ParedesRodríguez et $\mathrm{al}^{(28)}$ but contrasts Torabi et al ${ }^{29}$ who reported a statistically significant gender association $(p<0.05)$ in a study which had a female population twice that of the male.

The statistically significant higher mean OHIP-14 scores of subjects with cheek biting habits $(p<0.01)$ may be due to the trauma that has been known to accompany the habit. But in the case of those with systemic conditions and those without $(p=0.03)$, a relationship between the systemic condition and their OHROOL is not readily apparent. Perhaps the higher mean OHIP-14 scores was merely a reflection of their general quality of life and not necessarily their oral-health related quality of life.

There was no statistically significant association between OHRQoL and OML in contrast with to Torabi et al $^{(29)}$ who reported an association $(p=0.0006)$. The reason for this stark contrast would be apparent when the types of OMLs seen in both studies are examined. While Torabi et al reported a result among patients in the clinical setting who presented at the hospital to seek care for their OMLs, this report is from a population-based epidemiological study revealing mostly unnoticed oral mucosal lesions and physiologic variants.

Among the oral mucosa lesions observed in this study, the highest OHIP-14 score was seen in the group with recurrent aphthous stomatitis (RAS) as also reported by Taboli et $\mathrm{al}^{30}$ and Rajan et $\mathrm{al},{ }^{1}$ but in contrast with Torabi et $\mathrm{a}^{29}$ who reported the highest OHIP score in patients with Erythema multiformes. The subject with irritation fibroma recorded an OHIP14 score of 6.00 which suggested that the lesion had little or no impact on her quality of life. Rajan et al ${ }^{13}$ and Krisdapong et a $\mathrm{l}^{32}$ also reported that patients with RAS and pemphigus had worse quality of life than patients with leukoplakia, lichen planus and other benign exophytic lesions.

It is noteworthy that only the subjects with RAS, Commissural lip pits and physiologic pigmentation had mean OHIP-14 scores higher than the population average. While RAS might cause pain and functional 
limitations, commissural lip pits and physiologic pigmentations are mostly of aesthetic concern which is an important issue in adolescents as reflected in the subscale scores where psychological discomfort came second only to physical pain. This implies that patients with these conditions have a worse oralhealth related quality of life compared to the average individual in the same age category.

Also, the low OHIP scores seen in geographic tongue and linea alba is not surprising. While geographic tongue is mostly asymptomatic, linea alba is usually discovered upon routine checkup or when more impactful lesions are being investigated. Immunologic diseases, infections, and malignancies were not recorded in this study but their impacts on the quality of life of patients have been described in various studies. ${ }^{29-31}$

\section{CONCLUSION}

The most prevalent oral mucosal lesions in the adolescent age group are those of developmental origin. Quality of life was negatively impacted by the presence of systemic diseases as well as cheek biting habit. Hence, attention should be paid to the presence of systemic diseases as well as causes and aggravators of cheek biting and oral habits in adolescent patients seeking dental care.

\section{RECOMMENDATIONS}

A larger study involving urban populations is necessary to capture a wider range of habits and lesions. Also, there is a need to study the association between specific oral mucosal lesions and their effects on the quality of life of patients in order to be able to approach the management of these lesions holistically.

\section{Acknowledgements}

The authors would like to thank $\operatorname{Dr} U$. I Ekowmenhenhen for his logistical support.

\section{Financial Support}

Nil

\section{Conflict of interest}

None declared

\section{REFERENCES}

1. Ali M, Joseph B, Sundaram D. Prevalence of oral mucosal lesions in patients of the Kuwait University Dental Center. Saudi Dent J [Internet]. 2014; 25:111-8. Available from: http://dx.doi.org/10.1016/j.sdentj.2013.05.0 03
2. Feng J, Zhou Z, Shen X, Wang Y, Shi L, Wang Y, et al. Prevalence and distribution of oral mucosal lesions: A cross-sectional study in Shanghai, China. J Oral Pathol Med 2015; 44:490-4.

3. da Silva $K D$, Wellington $W L$, Sarkis-Onofre $R$, Aitken-Saavedra JP, Demarco FF, Correa MB, et al. Prevalence of oral mucosal lesions in population-based studies: A systematic review of the methodological aspects. Community Dent Oral Epidemiol. 2019; 47:431-40.

4. Majorana A, Bardellini E, Flocchini P, Amadori F, Conti G, Campus G. Oral mucosal lesions in children from 0 to 12 years old: Ten years' experience. Oral Surgery, Oral Med Oral Pathol Oral Radiol Endodontology [Internet]. 2010; 110(1):e13-8. Available from: http://dx.doi.org/10.1016/j.tripleo.2010.02. 025

5. Mouchrek MMM, Gonçalves LM, Bezerra-Júnior JRS, Maia E de CS, da Silva RA, da Cruz MCFN. Oral and maxillofacial biopsied lesions in Brazilian pediatric patients: A 16-year retrospective study. Rev Odonto Cienc. 2011; 26:222-226.

6. Trock B. Out of the Mouths of Babes: Oral Premalignant Lesions and Use of Alternative Tobacco Products. Cancer Epidemiol Biomarkers Prev. 2000; 9:637-638.

7. Sischo L, Broder HL. Oral Health-related Quality of Life: What, Why, How, and Future Implications. J Dent Res. 2011; 90:1264-1270.

8. Sawyer DR, Taiwo EO, Mosadomi A. Oral anomalies in Nigerian children. Community Dent Oral Epidemiol. 1984; 12:269-273.

9. Slade G. Concepts of Oral Health, Disease and the Quality of Life. In: Slade G, editor. Measuring Oral Health and Quality of Life. Chapel Hill, North Carolina.; 1997. p. 1-172.

10. Neville BW, Damm DD, White DH. Color Atlas of Clinical Oral Pathology. 2nd Edition. Hamilton, Ontario: BC Decker Inc; 2003.

11. Chauhan AS, Saha S, Reddy LVK, Sinha PM. Prevalence of Oral Mucosal Lesions and Normal Variants of the Oral Mucosa in 12 to 15 -year-old School Students in Lucknow - A Cross-Sectional Survey. Int J Oral Care Res. 2018; 6:50-53. 
12. Amadori F, Bardellini E, Conti G, Majorana A. Oral mucosal lesions in teenagers: a crosssectional study. Ital J Pediatr. 2017; 43(50).

13. Ünür M, Bektaş-kayhan K, Altop MS, Boy-metin $Z$, Keskin $Y$. The prevalence of oral mucosal lesions in children: A single centre study. J Istanbul Univ Fac Dent. 2015; 49:29-38.

14. Kamble K, Guddad S, Nayak A, Suragimath A, Sanade A. Prevalence of Oral Mucosal Lesions in Western Maharashtra: A Prospective Study. J Indian Acad Oral Med Radiol. 2017; 29(4):282.

15. Sandeepa NC, Jaishankar HP, B SC, Abhinetra MS, Darshan DD, Nappalli D. Prevalence of oral mucosal lesions among Pre-University students of Kodava population in Coorg District. J Int Oral Heal. 2013; 5:35-41.

16. Flaitz CM, Felefli S. Complications of an unrecognized cheek biting habit following a dental visit. Pediatr Dent. 2000; 22:511-2.

17. Kumar S, Kumar T, Rani V. Linea Alba Buccalis a Normal Anatomic Variation of Oral Cavity, Not an Oral Cancer, Awareness among Patients and Professionals: A Case Report. Sch J Dent Sci. 2016; 3:124-5.

18. Adeyeye O. Cigarette smoking habit among senior secondary school students in Lagos, southwest Nigeria. Int J Biol Med Res. 2011; 2:1047-1050.

19. Tailor MN, Joshi MU. Prevalence of commissural lip pits in population of central Gujarat: a hospital-based study. J Oral Maxillofac Pathol. 2008; 22(1).

20. Schaumann B, Peagler F, Gorlin R. Minor craniofacial anomalies among a Negro population. I. Prevalence of cleft uvula, commissural lip pits, preauricular pits, torus palatinus, and torus mandibularis. Oral Surg Oral Med Oral Pathol. 1970; 29:566-575.

21. Oyetola EO, Mogaji IK, Aghor TO, Ayilara OA. Pattern of Presentation of Oral Ulcerations in Patients Attending an Oral Medicine Clinic in Nigeria. Ann Ibd Pg Med. 2018; 16:7-11.

22. Omoregie, OF; Okoh M. Oral ulcerative lesions: a review of 55 cases in Benin-city, Nigeria. Nig Dent J. 2013; 21(1).

23. Osuji $A E$, Nwogbo $A$, Nwankwo $B$. Ankyloglossia : Analysis of 56 Cases Seen in Port Harcourt, Rivers State, Nigeria. Otolaryngol (Sunnyvale). 2020; 10:1-3.
24. Fomete B, Agbara R, OT Osunde, SA Bello, AA Yunus, BAM Goni. Pattern and Presentation of Tongue Lesions in Kaduna, Nigeria: A 10-Year Review. Ann Med Health Sci Res. 2017; 7:157161.

25. Dosumu, Oluwole $O$ and Dosumu EB. Gingival Tissue Color Related With Facial Skin and Acrylic Resin Denture Base Color in a Nigerian Population. Afr J Biomed Res. 2010; 13:107-111.

26. Singh V, Giliyar SB, Kumar $S$, Bhat $M$. Comparative Evaluation of Gingival Depigmentation by Diode Laser and CASE SERIES Comparative Evaluation of Gingival Depigmentation by Diode Laser and Cryosurgery Using Tetrafluoroethane: 18Month Follow-Up. Clin Adv Periodontics. 2012; 2:129-234.

27. Isiekwe I, Onigbogi O, Olatosi O, Sofola OO. Oral Health Quality of Life of a Nigerian University Undergraduate population. Available at https://www.researchgate.net/publication/ 280683213. 2014

28. Paredes-Rodríguez V-M, Torrijos-gómez G, González-serrano J, López- Pintor-Muñoz R-M, López-Bermejo M-Á, Hernández-Vallejo G. Quality of life and oral health in elderly. J Clin Exp Dent $\cdot$. 2016;E1-7.

29. Torabi M, Haghani J, Ghasemi AS, Afshar MK. Oral Health Related Quality of Life ( OHIP-14) In Patients with Oral Mucosal Diseases Attending to Afzalipour Hospital and Dental School, Kerman, Iran ( A Case - Control Study ). Sch J Dent Sci. 2017; 4:358-361.

30. Tabolli S, Bergamo F, Alessandroni L, Di Pietro C, Sampogna F, Abeni D. Quality of life and psychological problems of patients with oral mucosal disease in dermatological practice. Dermatology. 2009; 218(4):314-320.

31. Rajan B, Ahmed J, Shenoy N. Assessment of Quality of Life in Patients with Chronic Oral Mucosal Diseases: A Questionnaire-Based Study. Perm J. 2014; 18:123-127.

32. Krisdapong S, Sheiham A, Tsakos G. Impacts of recurrent aphthous stomatitis on quality of life of 12- and 15-year-old Thai children. Qual Life Res. 2012; 21:71-76. 